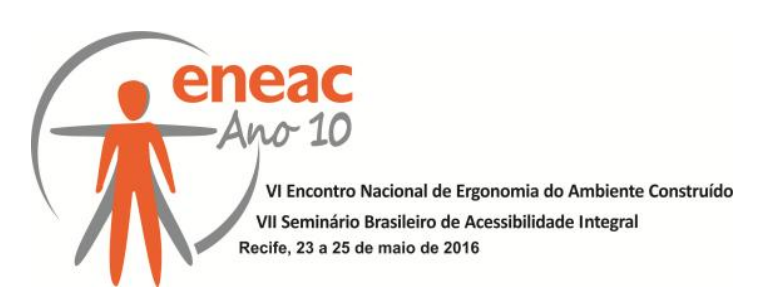

\title{
ACESSIBILIDADE EM BANHEIROS: UM ESTUDO TEÓRICO SOBRE AS NECESSIDADES DE INDIVÍDUOS ACONDROPLÁSICOS
}

\author{
VASCONCELOS, Hortência Lira de. (1); \\ BARROS, Bruno Xavier da Silva. (2) \\ (1) Universidade Federal de Pernambuco, Graduanda \\ e-mail: hortencia_lira@yahoo.com.br \\ (2) Universidade Federal de Pernambuco, Mestre \\ e-mail: barros_bruno@hotmail.com
}

\begin{abstract}
RESUMO
Ao redor do mundo, milhares de pessoas convivem com Acondroplasia e com as dificuldades decorrentes da utilização de ambientes que não consideram suas necessidades. Também conhecido como Nanismo, este grupo de condições genéticas determina características físicas específicas nestes indivíduos, os quais habitualmente fazem uso de ambientes configurados para pessoas sem esta disfunção, ou ambientes ditos acessíveis (NBR 9050, 2015), no entanto esta configuração dimensional não contempla pessoas acondroplásicas. Esta pesquisa teórica faz parte de um conjunto de estudos que objetiva a análise das características anatômicas gerais dos portadores de Acondroplasia, evidenciando necessidades e requisitos para uma concepção consciente de banheiros.
\end{abstract}

Palavras chave: acondroplasia; acessibilidade; banheiro.

\begin{abstract}
Around the world, thousands of people living with achondroplasia and the difficulties arising from the use of environments that do not consider their needs. Also known as dwarfism, this group of genetic conditions determines specific features in these individuals, which usually make use of configured environments for people without such disorder or accessible environments (in terms of NBR 9050, 2004), however this dimensional configuration does not include achondroplasic people. This theoretical research is part of a set of studies that objective analysis of general anatomical features of patients with achondroplasia, highlighting needs and requirements for a conscious design of bathrooms.
\end{abstract}

Keywords: achondroplasia; accessibility; bathrooms.

\section{INTRODUÇÃO}

A referente pesquisa aborda o Nanismo Acondroplásico, seus portadores possuem estatura muito inferior da considerada normal, homens normalmente possuem estatura de $1,45 \mathrm{~m}$, as mulheres possuem a estatura um pouco menor, cerca de 1,40m (GONZALEZ e MARCONDES, 1982). De acordo com Pottes (2010), existe em média 1 anão para cada 1 mil habitantes, mas não há confirmação exata da quantidade de portadores de Acondroplasia no Brasil. Sendo a síndrome que apresenta mais antigos registros na história, 


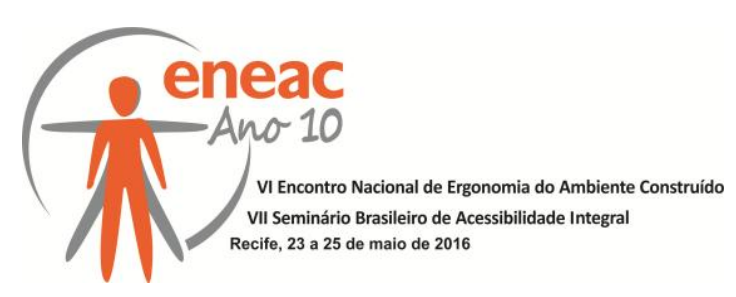

há evidencias com mais de 7.000 anos, em esqueletos encontrados na Grã Bretanha, além de restos ósseos de índios americanos encontrados na Flórida e no Alabama, com idade estimada entre 2.000 e 3.000 anos (CARDOSO et al, 2009).

Segundo Thomazelli (2004), é possível detectar o problema por ultrassonografia, a partir do 5 mês de gestação. Não é possível evitá-lo, mas em alguns casos dá para desenvolver estatura com tratamento à base de hormônio de crescimento ou cirurgia. Porém o efeito é o de "alongamento de ossos", preservando-se outras características.

De acordo com Cervan et al (2008), os Acondroplásicos se caracterizam principalmente pela baixa estatura, desproporção tronco/membros, com membros curtos e predomínio do segmento proximal, calota craniana normal, fisionomia característica com fronte proeminente e depressão da ponte nasal. A mandíbula é ressaltada e grande em relação aos ossos da face, bem como os dentes são sobrepostos e mal alinhados gerando má oclusão10. As mãos são pequenas e largas, e os dedos curtos com separação entre a terceira e quarta falanges (mão em tridente). Ainda segundo a autora, Não há prejuízo do desenvolvimento mental, mesmo nos casos que apresentam a referida hidrocefalia, que pode estar presente na infância. A inteligência não é afetada e muitos acondroplasicos são, na verdade, dotados de inteligência acima da média.

Tosta (2005), enfatiza a falta de politicas públicas voltadas aos portadores de acondrolpasia no Brasil, por diversas vezes sofrem um esquecimento por parte das autoridades responsáveis pelo desenvolvimento do bem estar social de seus cidadãos. Dentro deste contexto, vale ressaltar que em 1991 surgiu a primeira lei de inclusão a pessoa com deficiência mas não incluia o nanismo. Segundo o Censo 2010 cerca de 45,6 milhões de pessoas declarou ter ao menos um tipo de deficiência, o que equivale a $23,9 \%$ da população brasileira. No entanto, com o Decreto № 3.298, de 20 de dezembro de 1999, o nanismo passou a figurar entre as deficiências, representando um grande avanço na inserção de portadores de nanismo no mercado de trabalho. Contudo, o autor afirma que não se tem observado a prática de grandes mudanças.

Neste ponto ressaltamos a importância da Ergonomia no contexto de adaptação de artefatos às características, necessidades e limitações humanas. A ergonomia busca a harmonia entre interface humano-máquina, de modo que as tarefas, postos de trabalho, produtos, ambientes e sistemas tornem-se compatíveis com as necessidades, habilidades e limitações das pessoas. Para tanto, faz uso de dados da Fisiologia, da neurofisiologia, psicofisiologia, da psicologia, da psicopatologia, da biomecânica ocupacional, bem como da anatomia e da antropometria. (MORAES e SOARES, 2010; MORAES E MONT'ALVÃO, 2010; IIDA, 2005).

Este estudo foi motivado pela carência de dados aplicáveis à composição de um ambiente que possa ser utilizado por pessoas com Acondroplasia e faz parte de um estudo mais amplo, com o propósito de demostrar, através de pesquisas teóricas e exploratórias, a notória necessidade dos portadores de Acondroplasia ao utilizar ambientes comuns e necessários.

\section{FUNDAMENTAÇÃO TEÓRICA}

Conforme Lopes et al (2008), a Acondroplasia é causada por mutações genéticas. O autor afirma que pessoas de estatura normal, mesmo sem ascendentes com a mesma anomalia, podem gerar filhos acometidos por essa displasia esquelética. As características mais comuns são a baixa estatura e pernas e braços encurtados e desproporcionais ao tamanho da cabeça e ao comprimento do tronco, contudo, alguns de seus órgãos possuem tamanho maior em relação a sua altura. Ainda conforme o autor, o encurtamento dos membros ocorre principalmente na parte superior dos braços e nas coxas. Adultos têm uma curva 


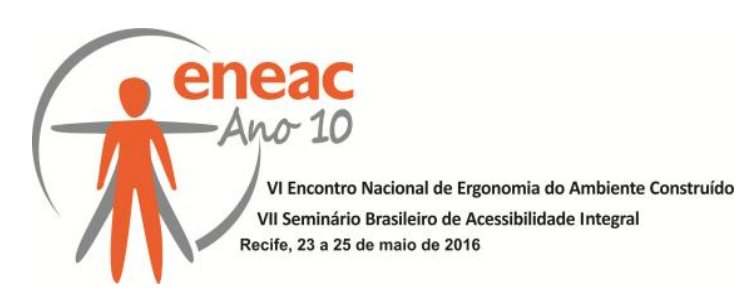

acentuada no final da coluna vertebral, quase sempre possuem pernas curvas e podem apresentar limites na movimentação dos cotovelos.

De acordo com Thomazelli (2004), o problema mais comum, responsável por $70 \%$ dos casos, é impedimento do desenvolvimento normal dos ossos longos, como o fêmur e a tíbia (figura 02), os membros se encurtam, mas o tronco tem tamanho próximo ao normal, pode ser diagnosticado a partir do quinto mês de gestação, pais mais velhos do que 45 anos tem possibilidade maior de ter filhos com determinadas doenças genéticas, incluindo Acondroplasia. As principais características dos indivíduos acondroplasicos são (TOMAZELLI, 2004; AIN, 2004; GOLLUST et al., 2003; HO, 2004):

- Depressão do dorso nasal ("nariz em sela"), a cabeça dos acondroplásicos é desproporcionalmente maior em relação ao corpo, caracterizando a macrocefalia;

- As mãos são pequenas e largas, e os dedos curtos com separação entre a terceira e quarta falanges;

- Problemas ortopédicos moderados ou severos, encurvamento da coluna e das pernas;

- Apneia central: parada temporária da respiração por compressão das estruturas cerebrais ou da coluna vertebral, infecções frequentes de ouvido, causando perda auditiva leve a moderada;

- Hidrocefalia: crescimento exagerado do crânio por excesso de líquido no cérebro, devido ao pequeno tamanho dos orifícios de drenagem localizados no encéfalo;

- Membros superiores e inferiores encurtados.

A proporção entre os ossos do fêmur e tíbia e o restante do corpo (figura 01) demostra a grande dificuldade que indivíduos com Acondroplasia possuem para se sentarem em superfícies de determinadas alturas, posição usual para utilizar o vaso sanitário.

Figura 01: Radiografia de um portador de Acondroplasia.

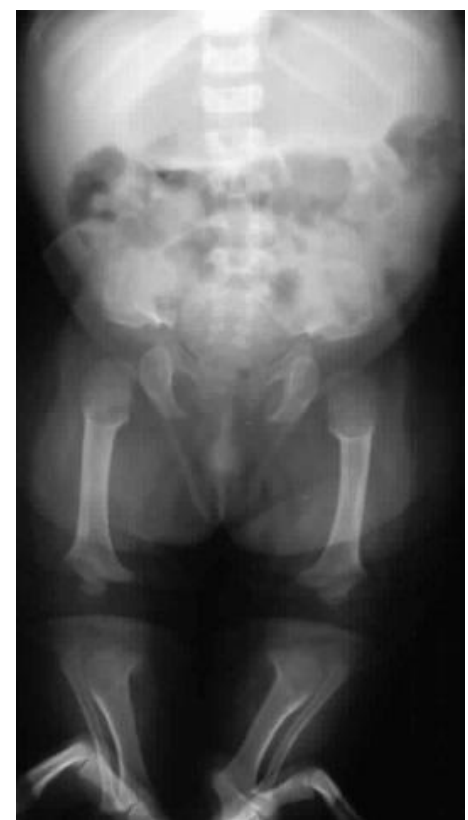

Fonte: http://emedicine.medscape.com/article/415494-overview\#a2

É comum entre pessoas com nanismo a sensação de falta de respeito e reconhecimento como indivíduos, pois muitas vezes acabam sendo ridicularizados e tratados de forma 


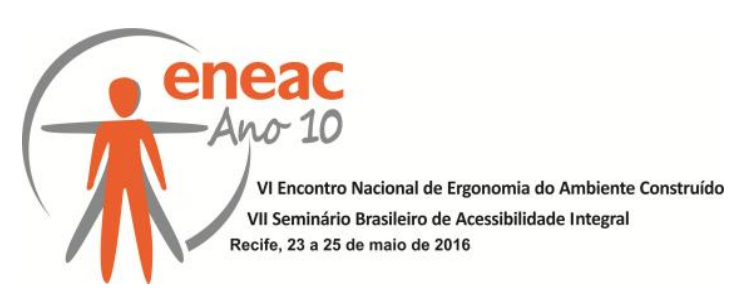

infantilizada devido a sua baixa estatura (CERVAN et al., 2008). Para além das dificuldades de relacionamento na sociedade, pessoas com nanismo também sentem problemas em suas atividades de vida diária.

Apesar de ser considerada uma deficiência física, pessoas com nanismo possuem longevidade normal, podendo ter uma vida íntegra e produtiva na sociedade. Porém, muitos portadores de nanismo estão propensos a desenvolver distúrbios psicológicos relacionados ao complexo de inferioridade e a insatisfação com a aparência física (CERVAN et al., 2008).

Vieira et al. (2005) levantam dados sobre tais dificuldades, por aspectos relacionados à utilização do espaço físico circundante e o acesso ao próprio corpo. Com relação à autoestima, surgem desafios nos cuidados de higiene pessoal (pés, região perineal e região dorsal), e para vestir-se de acordo com seu gosto pessoal, visto que pessoas com nanismo enfrentam grande dificuldade em encontrar roupas de tamanho adequado às suas dimensões corporais.

Segundo Panero e Zelnik (2013), a antropometria é a ciência que trata especificamente das medidas do corpo humano para determinar diferenças em indivíduos e grupos. O valor do dimensionamento humano aplicado a projetos reside no fato de que "os dados antropométricos definem as medições de tamanho, peso e proporção do corpo humano, aplicáveis a um correto dimensionamento de projeto de produtos, equipamentos e postos de trabalho" (MORAES e MONT'ALVÃO, 2010; IIDA, 2005). Baseado nessas informações tende a projetar um ambiente que se adeque as medidas e necessidades humanas, provendo assim maior conforto e segurança ao nosso usuário. O banheiro é um dos maiores desafios diários para pessoas com deficiências físicas ou necessidades especiais.

O projeto ergonômico deve integrar o homem à edificação ou aos ambientes em que vive, por isso é essencial possibilitar que qualquer indivíduo possa adaptar-se às condições ambientais de diversos espaços. A falta de estudos ergonômicos para portadores de necessidades especiais, como crianças, idosos e portadores de deficiência, vem criando grandes dificuldades na concepção e adaptação dos espaços públicos e privados. (TEODOLINO et al.,2006).

A norma Brasileira ABNT NBR 9050/2015 difunde requisitos sobre os diversos itens utilizados no ambiente de estudo, para torná-lo acessível. O dimensionamento para estes itens incluem:

- Bacias sanitárias - altura entre 0,43m e 0,45m do piso acabado. Em conjunto com o assento a altura máxima permitida é $0,46 \mathrm{~m}$;

- Mictórios - altura 0,60m a 0,65 do piso acabado;

- Lavatórios - altura de 0,78m a 0,80m do piso acabado;

- Registros e duchas manuais- exclusivamente alavancas com utilização de monocomando, altura $1,00 \mathrm{~m}$ do piso acabado.

Contudo, as regras estabelecidas pela ABNT 9050:2015 são focadas na acessibilidade a cadeirantes e muletantes, deste modo, estabelecem parâmetros que não consideram as necessidades corpóreas dos portadores de nanismo, acarretando em diversos constrangimentos, riscos à saúde e adaptações artesanais para uma melhor utilização dos ambientes. 


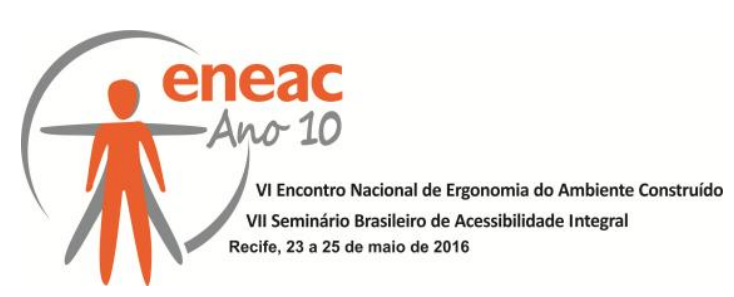

Figura 2: Portadora de Acondroplasia utilizando o banheiro residencial.

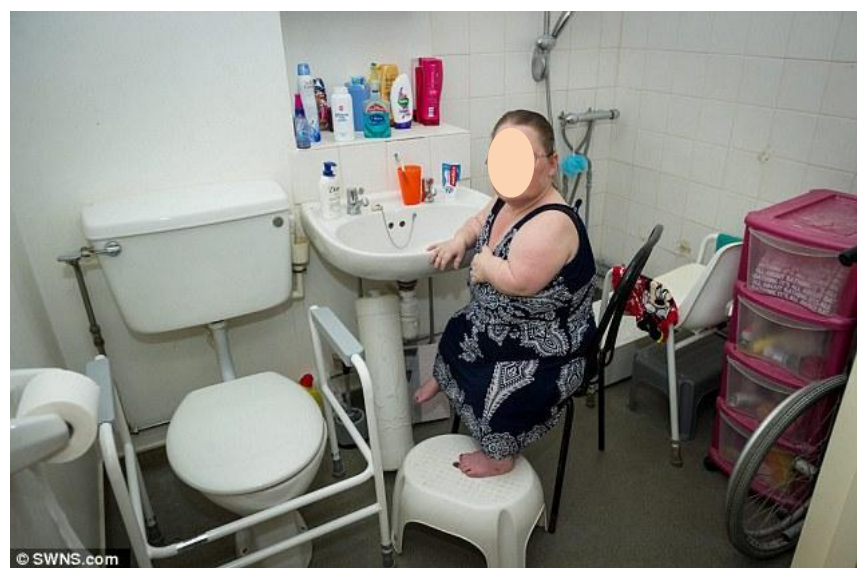

Fonte: http://www.dailymail.co.uk/news/article-3170679

A acessibilidade em banheiros residenciais deve resultar da investigação de tecnologia e dos elementos disponíveis, da legislação, da atuação profissional e, principalmente, ter como alicerce as características individuais dos usuários envolvidos. Um banheiro que não está de acordo com as prioridades e habilidades do sujeito afetando direta ou indiretamente o seu cotidiano (SCARAMUSSA, 2012). A adaptação em banheiros se torna a solução encontrada pela maioria que, ao se deparar com uma situação mobilidade reduzida, necessita reorganizar o espaço de maneira improvisada, a imagem 03 exigiu adaptações no banheiro da portadora, são encontradas cadeiras, e diversos apoios, utilizados como degraus, para que a usuária possa utilizar o ambiente. Também se verifica o uso de um andador sendo utilizado como barra de apoio para mãos e pés, auxiliando o uso do vaso sanitário. Este tipo de adaptação ressalta as diferenças entre as proporções de indivíduos acondroplásicos e não-acondroplásicos e evidencia a necessidade de artefatos de dimensões diferenciadas, os quais na maioria das vezes devem ter sua altura reduzida.

Figura 3: Portadora de Acondroplasia na posição sentada.

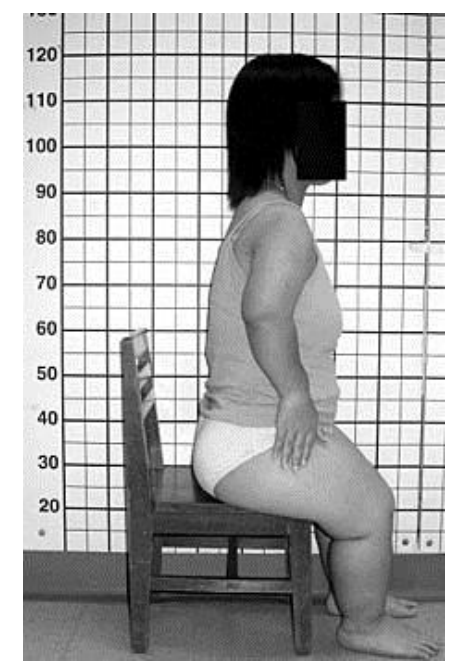

Fonte: http://www.hkjpaed.org/details.asp?id=95\&show=1234 


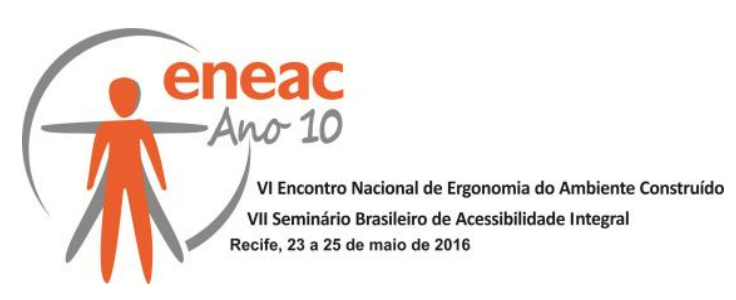

\section{METODOLOGIA}

No processo de estruturação da referente investigação, alicerçamo-nos sobre a ótica da Pesquisa Bibliográfica. Apoiados em Cervo, Bervian e da Silva (2007, p.61), nos guiamos no fato da pesquisa bibliográfica se constituir na busca do domínio do estado da arte sobre determinado tema. Desta forma, nos debruçamos sobre a literatura científica com o intuito de identificar insumos teóricos que fornecessem referências tanto em relação às divergências físicas nas características do indivíduo portador de Acondroplasia, quanto na necessidade do uso de banheiros públicos e sociais.

Com o intuito de demostrar a recorrente falta de acessibilidade para com os portadores de nanismo, outro método de pesquisa se fez necessário, o Método Comparativo. Em concordância com Lakatos e Marconi (2011), a seleção deste método se deu por sua essência na realização de comparações com a finalidade de verificar semelhanças e explicar divergências.

Sendo assim, o método comparativo se fez necessário para atender o objetivo de comparar as características do indivíduo portador de Acondroplasia, com as características dos indivíduos considerados normais, levando-nos a visualização de forma mais clara, da grande diferença entre as proporções corporais destes públicos.

\section{RESULTADOS}

Corroboramos com Cervan et al. (2008) quando enfatiza o quão são necessárias ações que valorizem a independência, a autonomia e o bem estar dessas populações. A situação de doença ou deficiência é, para muitos, sinônimo de exclusão social, isolamento familiar e vulnerabilidade que geram estigmas individuais e coletivos. É de suma importância incentivar novas pesquisas, despertar, conscientizar, propor soluções e fomentar discussões frente às diversidades, contribuindo para uma mudança cultural da sociedade e para a qualidade de vida das pessoas portadoras de deficiências. Desta forma, o projeto de um banheiro público também deve considerar as necessidades das pessoas com nanismo, incluindo-as na sociedade e oferecendo a elas o que se oferece a qualquer indivíduo, nada a mais e nada a menos, apenas a mesma forma de tratamento.

Os padrões dimensionais constantes na Norma de Acessibilidade NBR 9050:2015 (já especificadas anteriormente na fundamentação teórica) são os valores utilizados para projetar banheiros acessíveis, no entanto, o foco da Norma repousa sobre a utilização de cadeira de rodas ou muletas, em momento algum os indivíduos acondroplásicos são mencionados ou considerados.

A anatomia do portador de Acondroplasia é visivelmente diferente do usuário ao qual a norma NBR 9050:2015 destina-se, o que faz com que estes usuários necessitem de um padrão projetual e recomendações específicas. Desta forma, a partir do estudo das características corpóreas de indivíduos com nanismo, foi possível pontuar requisitos a serem considerados no projeto de banheiros. A Tabelas 1 e 2 que se seguem citam os elementos pertencentes ao banheiro, o constrangimento ao qual o indivíduo com Acondroplasia pode vir a ser exposto e a solução proposta para adequação do elemento: 


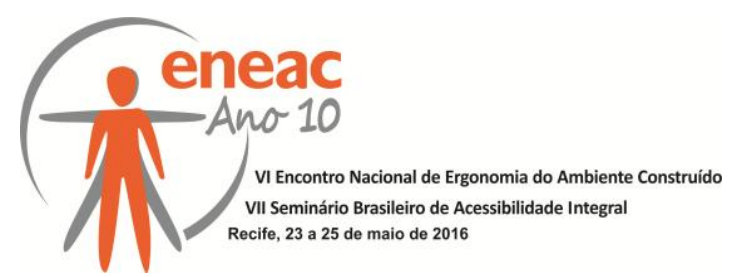

Tabela 1: Considerações projetuais para banheiros acessíveis a indivíduos acondroplásicos.

\begin{tabular}{|c|c|}
\hline $\begin{array}{l}\text { s } \\
\text { irias }\end{array}$ & $\begin{array}{l}\text { A altura }(0,43 \mathrm{~m} \text { e } 0,45 \mathrm{~m}) \text { impossibilita a posição correta de utilização, o } \\
\text { portador de Acondroplasia não possui a dimensão necessária nos } \\
\text { membros inferiores, que o permita sentar-se a essa distância do solo e } \\
\text { permanecer com os pés apoiados no chão. Recomenda-se o uso de } \\
\text { base fixa na altura ideal para o apoio dos pés, ou o encurtamento } \\
\text { definitivo na altura da bacia sanitária. } \\
\text { Há também necessidade de modificação da profundidade do assento, } \\
\text { uma vez que a inadequação desta dimensão pode causar grandes } \\
\text { transtornos na utilização, podendo o usuário cair dentro do vaso durante } \\
\text { o uso, é necessário diminuir as dimensões do objeto. }\end{array}$ \\
\hline $\begin{array}{l}\text { Caixas de } \\
\text { descarga }\end{array}$ & $\begin{array}{l}\text { A altura de } 1,00 \mathrm{~m} \text { para o acionamento da descarga conforme a } \\
\text { exigência normativa não condiz com a necessidade do acondroplásico, } \\
\text { sugere-se a redução desta altura e a instalação na lateral da bacia } \\
\text { sanitária, facilitando a acesso. Em conjunto às modificações de altura e } \\
\text { distancia, é importante ressaltar que o acionamento seja do tipo } \\
\text { alavanca ou a partir de mecanismos automáticos. }\end{array}$ \\
\hline Mict & $\begin{array}{l}\text { A altura padrão dos mictórios }(0,60 \mathrm{~m} \text { a } 0,65 \mathrm{~m}) \text { impossibilita o uso, sendo } \\
\text { necessário o uso de degrau móvel ou a instalação em uma altura } \\
\text { inferior. }\end{array}$ \\
\hline & $\begin{array}{l}\text { Esses itens necessitam de mais atenção, pois possuem altura de } \\
\text { instalação e profundidade inadequadas ao uso do acondroplásico, em } \\
\text { conjunto com itens que normalmente estão sobre os mesmos, itens } \\
\text { necessários à higiene, espelhos, porta objetos, toalhas, entre outros. A } \\
\text { adequação deverá ocorrer no projeto do mobiliário, pois, o uso de } \\
\text { apoios, continuará impossibilitando o uso, uma vez que os degraus só } \\
\text { auxiliam o acondroplásico a alcançar alturas. A profundidade dos itens } \\
\text { precisa respeitar o limite de alcance do usuário. }\end{array}$ \\
\hline $\mathbf{R e}$ & $\begin{array}{l}\text { A norma NBR } 9050 / 2015 \text { recomenda que o registro possua altura de } 1 \\
\text { m do chão acabado, para o portador de nanismo seria essencial que a } \\
\text { chave de registro fosse disposta mais próxima ao chão acabado, } \\
\text { proporcionando uma melhor execução da tarefa, ressaltando ainda que } \\
\text { o formato do registro deverá ser extremamente prático e simples, } \\
\text { levando em consideração o formado da mão dos portadores de } \\
\text { Acondroplasia. Seguindo a mesma recomendação as pias e pegas de } \\
\text { torneiras não podem possuir reentrâncias e/ou saliências, detalhes e } \\
\text { formato diferenciados podem prejudicar o manuseio, pois há uma maior } \\
\text { espessura dos dedos e uma reduzida mobilidade articular. }\end{array}$ \\
\hline $\begin{array}{l}\text { Vão abaixo } \\
\text { de portas } \\
\text { das cabines }\end{array}$ & $\begin{array}{l}\text { Comumente as portas das cabines de vasos sanitários em banheiros } \\
\text { públicos apresentam um espaço entre sua parte inferior e o chão. Para } \\
\text { evitar exposição e constrangimento do indivíduo com Acondroplasia, é } \\
\text { importante que este vão abaixo da porta tenha sua dimensão reduzida. }\end{array}$ \\
\hline $\begin{array}{l}\text { Porta } \\
\text { sabonetes e } \\
\text { utensílios de }\end{array}$ & $\begin{array}{l}\text { A instalação não deve seguir a altura padrão de } 1,20 \mathrm{~m} \text {. Os itens } \\
\text { utilizados durante o banho devem ser instalados de forma que } \\
\text { possibilitem o manuseio e a visualização. }\end{array}$ \\
\hline
\end{tabular}

Fonte: Elaborado pelos autores para a pesquisa. 


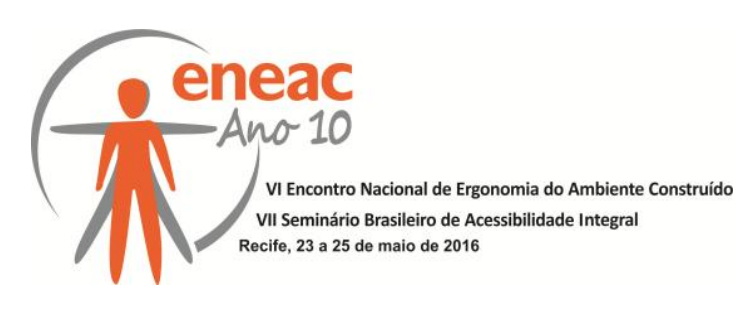

Além destes itens, podemos frisar outros elementos, os quais possuem ampla aplicabilidade projetual nos mais diversos ambientes, como por exemplo:

Tabela 2: Requisitos adicionais de ampla aplicabilidade.

\begin{tabular}{|l|l|}
\hline $\begin{array}{l}\text { Maçanetas de } \\
\text { portas }\end{array}$ & $\begin{array}{l}\text { A NBR 9050/2015 indica a instalação das maçanetas a uma altura } \\
\text { entre 0,90 e 1,10m, devem ter condições de serem abertas com um } \\
\text { único movimento e suas maçanetas devem ser tipo alavanca. Os } \\
\text { acondroplásicos possuem particularidades na formação das mãos, } \\
\text { seria ideal para uma melhor adequação ao uso, o puxador vertical, } \\
\text { podendo o mesmo ser instalado em menor altura em relação ao piso } \\
\text { acabado. }\end{array}$ \\
\hline $\begin{array}{l}\text { Interruptores } \\
\text { de iluminação }\end{array}$ & $\begin{array}{l}\text { A altura padrão para os interruptores e tomadas deve ser 1,20m do } \\
\text { piso acabado, essa altura pode ser ajustada de acordo com a } \\
\text { necessidade do usuário. O acionamento pode sofrer ajustes, pode-se } \\
\text { adequar para acionamento automático, detector de presença ou uso } \\
\text { de controle remoto. }\end{array}$ \\
\hline
\end{tabular}

Fonte: Elaborado pelos autores para a pesquisa.

Em tempo, cabe lembrar que a Acondroplasia não interfere nas funções cognitivas do portador, normalmente as dificuldades relacionadas à anomalia provêm de níveis de qualidade de vida, autoestima, acesso a educação e saúde física de qualidade. Com simples alterações em objetos cotidianos o portador de Acondroplasia poderá executar normalmente todas as tarefas realizadas por não portadores da anomalia.

\section{CONCLUSÃO}

A pesquisa reflete a necessidade eminente de consideração de indivíduos com Acondroplasia no projeto de banheiros. Os riscos de queda, as impossibilidades de higienização ou realização de necessidades fisiológicas são fatores relevantes demais para serem negligenciados. Em adição, não podemos esquecer-nos do constrangimento gerado ao ter que pedir auxílio para utilizar uma torneira ou tentar fazê-lo sem ajuda.

Tanto os dimensionamentos normais para banheiros, quanto o dimensionamento para banheiros acessíveis não são adequados para indivíduos portadores de Acondroplasia. Evidenciaram-se os elementos de inadequação dimensional, apontando sugestões de alteração projetual visando a inclusão deste público-alvo. É importante que a Associação Brasileira de Normas Técnicas insira as pessoas com nanismo em suas considerações na NBR 9050, pois uma norma que trata de acessibilidade deve buscar a inclusão.

Para a execução de projetos mais precisos, a pesquisa aponta a necessidade de um levantamento antropométrico exclusivo para pessoas com nanismo. São inúmeras as dificuldades encontradas pelos portadores desta anomalia, deste modo, faz-se extremamente importante o desenvolvimento de pesquisas que possam auxiliar na criação de padrões técnicos e/ou antropométricos, podendo assim disseminar ainda mais a autonomia e a inclusão do portador de nanismo na sociedade. É oportuno mencionar a importância de iniciativas desta natureza, esta pesquisa permitiu uma série de esclarecimentos sobre aspectos de adequação ergonômica de indivíduos acondroplásicos.

O desenvolvimento deste estudo aponta ainda para a necessidade de investigação de outros ambientes residenciais e públicos. Tais pesquisas também poderiam ser levadas a outras áreas, como, por exemplo, fornecer considerações ergonômicas ao projeto de 


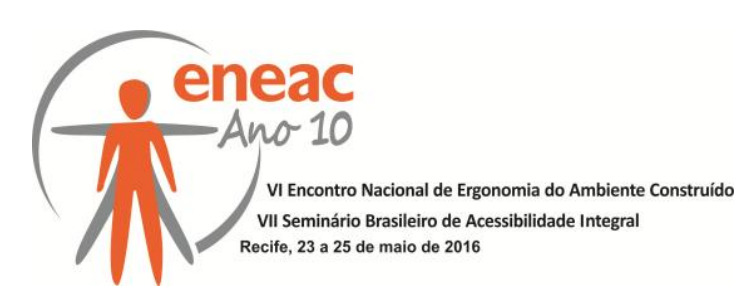

vestuário. A ergonomia deve ser sempre o foco em projetos, independentemente das limitações físicas ou cognitivas dos seres humanos.

\section{REFERÊNCIAS}

AIN, M.C.; BROWNE, J.A. Spinal arthrodesis with instrumentation for thoracolumbar kyphosis in pediatric achondroplasia. Spine. 2004;29:2075-80.

ASSOCIAÇÃO BRASILEIRA DE NORMAS TÉCNICAS. ABNT NBR 9050:2015 -

Acessibilidade a edifcações, mobiliário, espaços e equipamentos urbanos. ABNT, Rio de janeiro. 2015.

CARDOSO, R; AJZEN, S; SANTOS, K; FERNANDES, L; COSTA, C; OLIVEIRA, J; Características cranianas, faciais e dentárias em indivíduos acondroplásicos. Rev Inst Ciência Saúde, 2009;27(2):171-5.

CERVAN, Mariana Pereira; SILVA, Márcia Cristina Pires da; LIMA, Rodrigo Lopes de Oliveira; COSTA, Roberto Fernandes da. Estudo Comparativo do nível de qualidade de vida entre sujeitos acondroplásicos e não-acondroplásicos. Jornal Brasileiro de Psiquiatria [online]. 2008, vol.57, n.2, pp. 105-111.

GOLLUST S.E.; Thompson R.E. Gooding HC, Biesecker BB. Living with achondroplasia in an average-sized world: an assessment of quality of life. Am J Med Genet. 2003;120A :44758.

GONZALEZ, C.H.; MARCONDES, E. Caso em foco: acondroplasia. Pediat. São Paulo 4:62-66 1982.

GRANDJEAN, E. Manual de Ergonomia: Adaptando o trabalho ao homem. 5.ed. Porto Alegre: Artes Médicas, 2005.

HO, N.C.; GUARNIERI, M.; BRANT, L.J.; PARK, S.S.; SUN, B; NORTH, M. et al. Living with achondroplasia: quality of life evaluation following cervico-medullary descompression. Am J Med Genet. 2004;131A:163-7.

IIDA, Itiro. Egonomia: projeto e produção. 2ª edição. São Paulo: Edgard Blucher, 2005.

LIMA, R. O, SILVA, C.P, CERVAN, M.P.; COSTA R.F Acondroplasia: revisão sobre as características da doença. Centro de Esudos e Pesquisas Sanny - CEPS . Grupo de Pesquisa em Disfunção do Movimento Humano da Faculdade de Fisioterapia da UNISANTA, 2008.

LOPES, S, C, F. Acondroplasia: revisão sobre a doença. Centro de Estudos e

Pesquisas Sanny - CEPS - Grupo de Pesquisa em Disfunção do Movimento Humano da Faculdade de Fisioterapia da UNISANTA

MORAES, Anamaria; MONT'ALVÃO, Cláudia. Ergonomia: Conceitos e aplicações. Rio de Janeiro: 2AB, 2010.

PANERO, J., ZELNIK, M. Dimensionamento Humano para Espaços Interiores. Gustavo Gili, Barcelona, 2013.

POTTES, Hélio. Associação Gente Pequena do Brasil. 2010. Disponível em: www.gentepequena.org.br. Acesso em: 06/01/16.

SOARES, M. M. \& MORAES, A. de. Ergonomia Princípios e Métodos. Apostila Curso de Especialização - Departamento de Design, Universidade Federal de Pernambuco, 2003. 


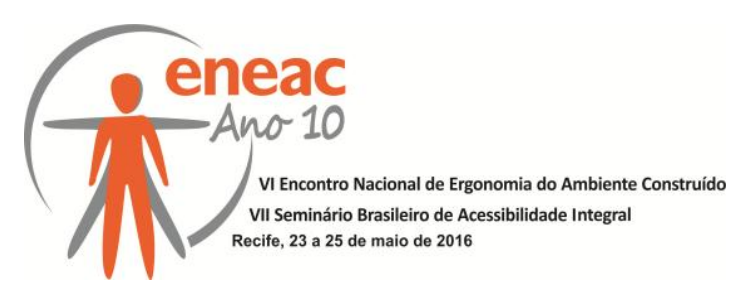

TEODOLINO, J.C.P. Utilização da NBR 9050 e do questionário bipolar na avaliação da acessibilidade de clínicas de fisioterapia 2006 - disponível em: Revista Brasileira de Ciências da Saúde, ano III.

THOMAZELLI, J. Entenda o Nanismo. Revista da Folha [online]. 2004 disponível em : <http://www1.folha.uol.com.br/revista/inde25072004.shl.> consultado em: 20/12/2015

TOSTA, F. A Acondroplasia. 2005 - disponível em :

<http://www.psicologia.pt/artigos/imprimir_l.php?codigo=TL0035> consultado : 20/12/2015 